\title{
Factors associated with arch reintervention and growth of the aortic arch after coarctation repair in neonates weighing less than $2.5 \mathrm{~kg}$
}

\author{
Tara Karamlou, MD, ${ }^{\mathrm{a}}$ Alessandra Bernasconi, MD, ${ }^{\mathrm{b}}$ Edgar Jaeggi, MD, ${ }^{\mathrm{b}}$ Fahad Alhabshan, MD, ${ }^{\mathrm{b}}$ William G. Williams, MD, ${ }^{\mathrm{a}}$ \\ Glen S. Van Arsdell, MD, ${ }^{\mathrm{a}}$ John G. Coles, MD, ${ }^{\mathrm{a}}$ and Christopher A. Caldarone, MD ${ }^{\mathrm{a}}$
}

\begin{abstract}
Objectives: Neonates weighing less than $2.5 \mathrm{~kg}$ with aortic coarctation are challenging. We sought to find the prevalence of death or aortic arch reintervention and their determinants after coarctation repair. We also sought to define growth trajectories for postrepair aortic arch dimensions and identify factors associated with accelerated longitudinal growth.
\end{abstract}

\begin{abstract}
Methods: We reviewed neonates weighing less than $2.5 \mathrm{~kg}$ undergoing coarctation repair between 1993 and 2004. Competing-risks methods determined time-related prevalences of death, arch reintervention, and survival without subsequent reintervention. Mixed regression analysis modeled longitudinal growth trajectories of echocardiographically derived aortic arch dimensions.

Results: Thirty-six neonates underwent coarctation repair. Initial repair type was simple end to end $(n=3)$, extended end to end $(n=16)$, subclavian flap aortoplasty $(n=15)$, and patch aortoplasty $(n=2)$. Median initial repair age was 11 days (range 2-69 days) and mean weight was $2.01 \pm 0.33 \mathrm{~kg}$. Overall 1-year survival was $76 \%$. After 1 year from initial repair, $19 \%$ had died without subsequent reintervention, $14 \%$ underwent arch reintervention, and $67 \%$ remained alive without arch reintervention. Neonates with extended end-to-end repairs had increased transverse aortic arch Z-scores $(P=.004)$. Although patients with larger initial transverse aortic arch Z-scores had higher scores across all time points $(P<.001)$, neonates with the smallest transverse aortic arch Z-scores had accelerated growth trajectories $(P<.001)$. Aortic isthmus growth was likewise accelerated in neonates with the smallest initial aortic isthmus Z-score $(P<.001)$.

Conclusions: Mortality and arch reintervention are common after initial repair of coarctation of the aorta in neonates weighing less than $2.5 \mathrm{~kg}$. Catch-up growth of both the transverse arch and isthmus occurs after coarctation repair, especially in those with the smallest arch parameters, and may be increased by using an extended end-toend technique.
\end{abstract}

Neonatal repair of aortic coarctation $(\mathrm{CoA})$ can be a technical challenge in patients weighing less than $2.5 \mathrm{~kg}$. In addition to the potential for recoarctation at the site of aortic anastomosis, in many patients there is hypoplasia of the aortic arch proximal to the anastomosis and uncertainty as to the ability of the proximal aortic arch to undergo "catch-up" growth (growth increased relative to somatic growth). ${ }^{1-8}$ Multiple surgical techniques can be used to repair CoA in small neonates, and the relationship of these techniques to the incidence of recoarctation and catch-up growth of the proximal aortic arch is important to understand. In the current study, we examine longitudinal aortic arch trajectories in

\footnotetext{
From the Division of Cardiovascular Surgery, Department of Surgery, ${ }^{\mathrm{a}}$ and Division of Cardiology, Department of Pediatrics, ${ }^{\mathrm{b}}$ University of Toronto, The Hospital for Sick Children, Toronto, Ontario, Canada.

Presented at the World Congress of Pediatric Cardiology and Pediatric Cardiothoracic Surgery, Buenos Aires, Argentina, 2005.

Received for publication Feb 7, 2008; revisions received June 21, 2008; accepted for publication July 26, 2008

Address for reprints: Christopher A. Caldarone, MD, The Hospital for Sick Children, 555 University Ave, Toronto, Ontario, Canada M5G 1X8 (E-mail: christopher. caldarone@sickkids.ca).

J Thorac Cardiovasc Surg 2009;137:1163-7

$0022-5223 / \$ 36.00$

Copyright (c) 2009 by The American Association for Thoracic Surgery

doi:10.1016/j.jtcvs.2008.07.065
}

low-birth-weight infants to characterize catch-up growth in the aortic arch and to relate these data to the type of surgical repair and the risk of recoarctation.

\section{PATIENTS AND METHODS \\ Study Subjects}

Patients weighing $2.5 \mathrm{~kg}$ or less who underwent initial CoA repair at the Hospital for Sick Children between January 1993 and June 2004 were identified from computerized databases. Inclusion criteria include biventricular physiology, concordant atrioventricular and ventriculoarterial connections, and classic coarctation of the thoracic aorta with and without hypoplasia of the aortic arch. Not included were patients with major and chromosomal abnormalities.

\section{Data Collection and Measurements}

The study was approved by the Institutional Research Ethics Board at the Hospital for Sick Children, and patient consent was waived. Data collected from medical record review included patient demographics, preoperative cardiac and noncardiac diagnoses, clinical condition, previous procedures and complications, echocardiographic and cardiac catheterization assessments and procedures, operative data, and postoperative and follow-up clinical status, including repeated echocardiographic measurements. Echocardiographic measurements included mean and peak gradients across the left ventricular outflow tract and dimensions across the aortic valve, the transverse arch, the aortic isthmus, and the descending aorta. Aortic dimensions were converted into Z-scores by regression equations based on previously published nomograms. ${ }^{9,10}$ 


\section{Abbreviations and Acronyms \\ $\mathrm{CoA}=$ coarctation of the aorta \\ $\mathrm{EEE}=$ extended end-to-end (anastomosis) \\ SEE $=$ simple end-to-end (anastomosis) \\ $\mathrm{VSD}=$ ventricular septal defect}

\section{Data Analysis}

Data are given as frequency, median with range, or mean $\pm \mathrm{SD}$ as appropriate, with the number of nonmissing values indicated. All data analyses were performed with SAS statistical software (version 9.1; SAS Institute, Inc, Cary, NC). Because of the small numbers of patients having patch aortoplasty $(\mathrm{n}=2)$ or resection with simple end-to-end (SEE) anastomosis $(n=3)$, only patients having either subclavian flap aortoplasty or resection with extended end-to-end (EEE) anastomosis were included in multivariable regression models. Both reintervention and mortality were modeled as time-dependent events by using both Kaplan-Meier estimates and parametric methods, with the association with risk factors being explored in multivariable analysis with bootstrap bagging ${ }^{11}$ to guide variable selection and assess reliability of inclusion in final regression models. Competing-risks analysis was used in a manner as previously reported. ${ }^{12,13}$ Post-CoA repair serial echocardiographic assessments of aortic valve and aortic arch dimension $\mathrm{Z}$-scores were modeled, and risk factors were sought by using mixed linear regression.

\section{RESULTS \\ Patient Characteristics}

During the study period, 36 children underwent initial CoA repair. Eighteen patients had ventricular septal defects (VSDs), including 6 with multiple VSDs. Two patients had atrioventricular septal defects, 2 patients had concomitant mitral valve stenosis, and 4 patients had subaortic stenosis. Prostaglandin was used in 27 patients before surgery. Initial repair type was SEE $(n=3)$, EEE $(n=16)$, subclavian flap aortoplasty $(n=15)$, and patch aortoplasty $(n=2)$. Operative approach was via a left posterolateral thoracotomy in all but 6 patients who underwent sternotomy. Four patients having sternotomy underwent resection with EEE repair, and 2 patients had patch aortoplasty. Concomitant intracardiac repairs were performed in 2 patients, repair of aortopulmonary window and right ventricle-pulmonary artery conduit placement. Median age at initial repair was 11 days (range 2-69 days) and mean weight was $2.01 \pm 0.33 \mathrm{~kg}$. Median initial aortic valve Z-score was-1.1 (range -5.7 to 2.5 ), median initial transverse aortic arch Z-score was -2.8 (range -9.5 to 0.3 ), and median initial aortic isthmus Z-score was -3.9 (range -14.1 to -0.2 ).

\section{Mortality and Arch Reintervention}

There were 8 deaths during the study period and 5 arch reinterventions (Table 1). Overall 1-year survival was 67\% before 1999, which improved to $90 \%$ thereafter $(P=.09)$. The one death after 1999 was unrelated to CoA repair, occurring after a urologic procedure. Competing-risks analysis predicted that after 1 year from the initial repair, $19 \%$ had died without subsequent reintervention, $14 \%$ underwent arch reintervention, and $67 \%$ remained alive without arch reintervention. Multivariable factors associated with arch reintervention included the presence of a VSD $(P=.06)$. We were unable to find any multivariable risk factors associated with mortality without reintervention.

\section{Longitudinal Assessment of Aortic Arch Growth}

Serial echocardiographic data $(n=135)$ were collected over a median interval of 9 months (range 0-5.4 years) after CoA repair with a median of 4 (range 1-11) measurements per patient. Nonlinear growth of all components of the aorta (including aortic valve, transverse arch, and aortic isthmus) occurred over time (Figure 1, $A$ to $C$ ). Baseline aortic valve $\mathrm{Z}$-score was positively correlated with the other measured

TABLE 1. Characteristics of patients having aortic arch reintervention or death

\begin{tabular}{|c|c|c|c|c|c|c|c|}
\hline GA (wk) & Sex & Weight (kg) & Age (d) & VSD & Associated lesions & Repair type & Approach \\
\hline \multicolumn{8}{|l|}{ Deaths $(\mathrm{n}=8)$} \\
\hline 40 & $\mathrm{~F}$ & 2.40 & 7.3 & Single & SAR & Subclavian flap & Thoracotomy \\
\hline 32 & $\mathrm{~F}$ & 2.30 & 14.6 & Single & None & Res Ex EEA & MS \\
\hline 36 & M & 2.20 & 3.7 & Single & None & Subclavian flap & Thoracotomy \\
\hline 35 & M & 1.46 & 0.3 & None & None & Res Ex EEA & Thoracotomy \\
\hline 37 & $\mathrm{~F}$ & 1.90 & 3.7 & None & None & Subclavian flap & Thoracotomy \\
\hline 36 & M & 2.00 & 65.7 & None & None & Res SEEA & Thoracotomy \\
\hline 37 & $\mathrm{~F}$ & 1.20 & 3.7 & Unk & None & Subclavian flap & Thoracotomy \\
\hline 40 & $\mathrm{~F}$ & 2.30 & 7.3 & Unk & None & Subclavian flap & Thoracotomy \\
\hline \multicolumn{8}{|c|}{ Reintervention $(\mathrm{n}=5)$} \\
\hline 40 & $\mathrm{~F}$ & 2.40 & 7.3 & Single & SAR & Subclavian flap & Thoracotomy \\
\hline 35 & M & 1.70 & 7.3 & Single & None & Subclavian flap & Thoracotomy \\
\hline 34 & $\mathrm{~F}$ & 1.90 & 29.2 & Single & MV abn & Res SEEA & Thoracotomy \\
\hline 36 & $\mathrm{~F}$ & 1.90 & 14.6 & None & None & Patch AoP & MS \\
\hline 35 & M & 2.26 & 3.7 & None & None & Res Ex EEA & Thoracotomy \\
\hline
\end{tabular}

$G A$, Gestational age; $w$, weeks; $k g$, kilograms; $d$, days; $S A R$, subaortic ridge; $V S D$, ventricular septal defect; $M V a b n$, mitral valve abnormality; $M S$, median sternototmy; $U n k$, unknown; Res Ex EEA, resection with extended end-to-end anastomosis; Res SEEA, resection with simple end-to-end anastomosis; Patch AoP, patch aortoplasty. 

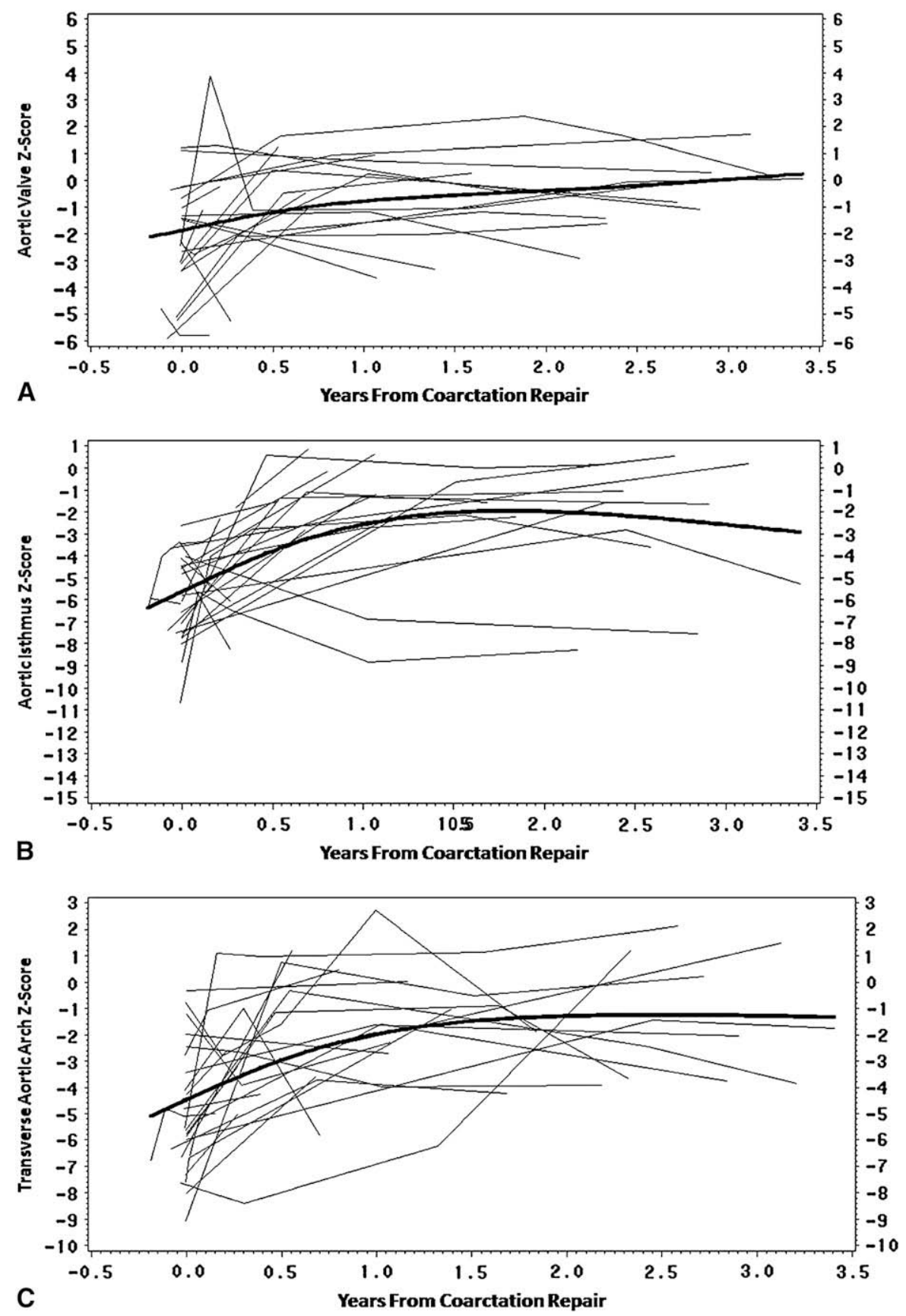

FIGURE 1. A, Growth of the Z-score of the aortic valve over time after coarctation repair was nonlinear and occurred in all patients over time. B, Similarly, growth of the Z-score of the aortic isthmus occurred nonlinearly over time after repair. C, Growth of the Z-score of the transverse aortic arch was also nonlinear and increased in all patients after initial coarctation repair. In all plots, the light black lines show the individual measurements over time since the initial coarctation repair, and the darker black line is a smoothing spline that represents the average trend in Z-score over time.

arch components as well as mitral valve stenosis, demonstrating that multiple in-series left-sided lesions are commonly seen in neonates undergoing repair (Table 2). Change in aortic valve Z-score had important correlation with baseline anatomic and procedural characteristics (Table $3)$. Of note, initial Z-score of the aortic valve and the trans- verse arch were negatively correlated with an increase in aortic valve growth, indicating that smaller beginning aortic valve $\mathrm{Z}$-score and smaller transverse arch led to a larger change in the Z-score of the aortic valve over time. Resection with EEE, conversely, was positively correlated with change in aortic valve Z-score over time, indicating that 
TABLE 2. Correlation between baseline aortic valve $Z$-score and other baseline covariables

\begin{tabular}{lcc}
\hline \multicolumn{1}{c}{ Variable } & $\boldsymbol{R}^{\mathbf{2}}$ & $\boldsymbol{P}$ value \\
\hline Initial AV size $(\mathrm{mm})$ & 0.96 & $<.001$ \\
Initial TAA Z-score & 0.55 & $<.001$ \\
Initial isthmus Z-score & 0.36 & $<.001$ \\
Mitral valve stenosis & 0.36 & .002 \\
Female gender & -0.20 & .03 \\
Age at surgery & -0.14 & .11 \\
Weight at surgery & 0.14 & .11 \\
\hline
\end{tabular}

$A V$, Aortic valve; $T A A$, transverse aortic arch.

correction of arch hypoplasia, inherent in this repair, improves growth potential.

Factors associated with larger final transverse aortic arch Z-score among patients having EEE or subclavian flap aortoplasty. Increase in transverse aortic arch Z-score occurred in both groups of patients over time $(P<.001$; Table 4). Patients with larger initial transverse aortic arch Z-scores had higher transverse aortic arch Z-scores across all time points, but those with the smallest Z-scores (in the bottom quintile) had accelerated trajectories and may, eventually, catch up to the other patients, as shown in Figure 2. Resection with EEE, compared with other repair types, was also associated with increased growth trajectory of transverse aortic arch Z-score $(P=.004$; Table 4).

Factors associated with larger final isthmus $\mathbf{Z}$-score. Multivariable factors associated with larger isthmus Z-score were also sought and are shown in Table 4. Similar to what we showed previously, the patients with larger initial Zscores had the largest measured isthmus Z-scores over time, but the smallest patients grew the fastest.

\section{DISCUSSION}

We have reported longitudinal outcomes regarding aortic arch dimensions after repair of neonatal CoA and demonstrated that "catch-up" aortic arch growth is accelerated in those with the smallest initial parameters and among infants undergoing EEE anastomosis compared with those undergoing subclavian flap aortoplasty. Our numbers were too small

TABLE 3. Correlation between change in aortic valve $Z$-score over time since coarctation repair and anatomic and procedural characteristics

\begin{tabular}{lcc}
\hline \multicolumn{1}{c}{ Variable } & $\boldsymbol{R}^{\mathbf{2}}$ & $\boldsymbol{P}$ value \\
\hline Initial AVZ score & -0.54 & $<.001$ \\
Initial TAA Z-score & -0.52 & $<.001$ \\
Initial isthmus Z-score & -0.37 & .001 \\
Resection with EEE & 0.32 & .004 \\
Mitral valve stenosis & -0.30 & .008 \\
Weight at surgery & 0.20 & .08 \\
\hline
\end{tabular}

$A V Z$, Aortic valve Z-score; $T A A$, transverse aortic arch; $E E E$, extended end-to-end anastomosis.
TABLE 4. Incremental risk factors for longitudinal echocardiographic outcomes

\begin{tabular}{lcr}
\hline \multicolumn{1}{c}{ Variable } & $\begin{array}{c}\text { Regression } \\
\text { coefficient }( \pm \text { SE })\end{array}$ & $\begin{array}{c}\boldsymbol{P} \\
\text { value }\end{array}$ \\
\hline 1. For larger transverse aortic arch Z-score & $0.03 \pm 0.01$ & \\
$\quad$ Longer time interval (per 1 year)* & $1.01 \pm 0.29$ & $<.001$ \\
Larger initial TAA Z-score & $2.15 \pm 0.32$ & .004 \\
Resection with EEE & & \\
Interaction between smaller initial TAA & & $<.001$ \\
$\quad$ Z-score and time & & \\
2. For larger aortic isthmus Z-score & $0.05 \pm 0.01$ & $<.001$ \\
Longer time interval (per 1 year) $\dagger$ & $1.03 \pm 0.21$ & $<.001$ \\
Larger initial isthmus Z-score & & $<.001$ \\
Interaction between smaller initial isthmus & & \\
$\quad$ Z-score and time & & \\
\hline
\end{tabular}

$S E$, Standard error; $T A A$, transverse aortic arch; $E E E$, extended end-to-end anastomosis. *Quadratic effect of time. $\dagger$ Cubic effect of time. Interactions between time and covariables indicate more rapid growth trajectories and can be interpreted using graphic display (see figures).

to definitively evaluate the influence of SEE repair on aortic arch growth proximal to the repair. However, the idea that circumferential anastomosis with resection and end-to-end repair would constrain further growth potential was voiced by Gross and Hufnagel ${ }^{13}$ and Schuster and Gross ${ }^{14}$ in their early report of 500 patients undergoing repair in 1962. Later studies bore these early concerns out, with a reported recoarctation rate of $85 \%$ after resection and SEE in some series. ${ }^{15}$ Propelled by these suboptimal results, techniques that provide immediate relief of relative aortic "stenosis," including subclavian flap aortoplasty and EEE, were developed. $^{1-4}$ Although subclavian flap aortoplasty decreased

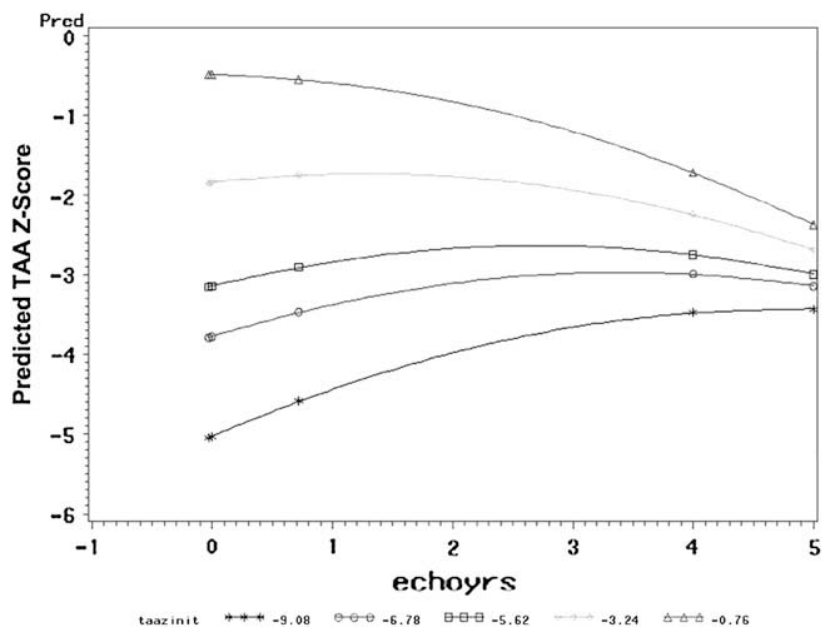

FIGURE 2. This graph shows the interaction between the initial transverse aortic arch (TAA) Z-score (vertical axis) and time (horizontal axis), modeled as a quadratic interaction. Initial TAA Z-scores have been grouped into quintiles (taazinit), shown by the different lines representing Z-score trajectories. Although the larger initial Z-scores have larger values across all time points, the smaller TAA Z-scores have accelerated growth trajectories compared with the larger TAA Z-scores. 
recoarctation rates, the inherent problems of left arm ischemia, growth or functional impairment, and late aneurysm formation decreased the enthusiasm for this type of repair. Additionally, subclavian flap aortoplasty is inadequate to correct tubular arch hypoplasia between the left common carotid artery and the left subclavian artery, both of which are frequently associated with $\mathrm{CoA} .{ }^{16,17}$

We also found a trend toward earlier reintervention in neonates with associated VSD. Brouwer and colleagues ${ }^{3}$ found a trend toward more severe aortic arch hypoplasia in patients with a VSD in their review of 15 consecutive infants with CoA undergoing SEE repair. In the setting of CoA and VSD, blood flow through the left ventricular outflow tract is reduced in proportion to the shunt fraction through the VSD, and it has been proposed that decreased aortic flow attenuates aortic growth during gestation. ${ }^{5,8}$

Although growth of the aortic arch has been noted in previous studies, catch-up growth (eg, growth out of proportion to somatic growth) has not been completely characterized. $^{3,4,18}$ Siewers and associates ${ }^{18}$ systematically assessed growth of the transverse arch after CoA repair in 102 children. They used aortic arch ratios to demonstrate growth in $32 \%$ of children using subclavian flap aortoplasty. Myers, McConnell, and Waldhausen ${ }^{4}$ used angiography to determine postoperative aortic arch growth at 1 year after repair in children undergoing subclavian flap aortoplasty. Using an age-matched control group without CoA, they found that neonates undergoing repair before 1 month of age experienced more postoperative growth (as a percent diameter increase from preoperative values) in the transverse arch immediately proximal to the CoA site than older children. Importantly, postoperative diameters in these two studies were absolute diameters or indexed aortic arch ratios, rather than $\mathrm{Z}$-values, and thus cannot be used to infer growth disproportionate to somatic growth. Our study provides evidence of longitudinal catch-up growth after repair that is most rapid in the early postoperative period. The rapid increase in Z-score postoperatively reflects the large number of patients in our series having repairs other than SEE. Rapid rise in diameter of socalled hypoplastic arches within 6 months after repair was also reported in the study by Brouwer and colleagues. ${ }^{3}$

In interpreting these data, we believe that complete relief of obstruction within all underdeveloped regions of the aortic arch is essential in promoting postoperative growth. Many neonates with important CoA have concomitant underdevelopment of the transverse and proximal arch. The "relative", stenoses within these proximal segments not only increase the risk of reintervention, but also are associated with impaired exercise performance in children with acceptable transaortic gradients at rest. ${ }^{19}$ The EEE pro- vides the optimum method for repair, in that it is addresses proximal obstruction and normalizes growth-inducing flow. The finding in the present report that a small aortic arch retains the potential for catch-up growth after adequate relief of obstruction is important in planning surgical repair. Perhaps even more important, the smallest patients with the most hypoplastic aortic arches may have increased benefit from this technique, possibly neutralizing the higher risk of recoarctation associated with CoA repair in low-birthweight infants.

\section{References}

1. Quaegebeur JM, Jonas RA, Weinberg AD, Blackstone EH, Kirklin JW. Congenital Heart Surgeons Society. Outcomes in seriously ill neonates with coarctation of the aorta. J Thorac Cardiovasc Surg. 1994;108:841-54.

2. Backer CL, Mavroudis C, Zias EA, Amin Z, Weigel TJ. Repair of coarctation with resection and extended end-to-end anastomosis. Ann Thorac Surg. 1998;66: 1365-70.

3. Brouwer MHJ, Cromme-Dijkhuis AH, Ebels T, Eijgelaar A. Growth of the hypoplastic aortic arch after simple coarctation resecetion and end-to-end anastomosis J Thorac Cardiovasc Surg. 1992;104:426-33.

4. Myers JL, McConnell BA, Waldhausen JA. Coarctation of the aorta in infants does the aortic arch grow after repair? Ann Thorac Surg. 1992;54:869-75.

5. Becker AE. Segmental aortic hypoplasia or how to interpret the flow concept. Int J Cardiol. 1988;20:247-55

6. Bruins CLDC. Competition between aortic isthmus and ductus arteriosus: reciprocal influence of structure and flow. Eur J Cardiol. 1978;8:87-97.

7. Shinebourne EA, Elseed AM. Relation between fetal flow patterns, coacrtation of the aorta and pulmonary flow. Br Heart J. 1974;36:492-8.

8. Hoffman JIE, Heymann MA, Rudolph AM. Coarctation of the aorta: significance of aortic flow. In: Anderson RH, Neches WH, Park SC, eds. Perspectives in pediatric cardiology. Mount Kisco (NY): Futura; 1988.

9. Daubeney PEF, Blackstone EH, Weintraub RG, Slavik Z, Scanlon J, Webber SA. Relationship of the dimension of cardiac structures to body size: an echocardiographic study in normal infants and children. Cardiol Young. 1999;9: 402-10

10. Sluysmans T, Colan SD. Theoretical and empirical derivation of cardiovascular allometric relationships in children. J Appl Physiol. 2004;1144-52.

11. Blackstone EH, Rice TW. Clinical-pathologic conference: choice and use of statistical methods for the clinical study "superficial adenocarcinoma of the esophagus." J Thorac Cardiovasc Surg. 2001;122:1063-76.

12. Karamlou T, Jang K, Williams WG, Caldarone CA, VanArsdell G, Coles JG, et al Outcomes and associated risk factors for aortic valve replacement in 160 children: a competing-risks analysis. Circulation. 2005;112:3462-9.

13. Gross RE, Hufnagel CA. Coarctation of the aorta: experimental studies regarding its surgical correction. N Engl J Med. 1945;233:287-93.

14. Schuster SR, Gross RE. Surgery for coarctation of the aorta: a review of 500 cases. J Thorac Cardiovasc Surg. 1962;43:54-70.

15. Kappetein AH, Zwinderman AJJC, Bogers AJ, Rohmer J, Huysmans HA. More than thirty-five years of coarctation repair: an unexpected high relapse rate. $J$ Thorac Cardiovasc Surg. 1994;107:87-95.

16. Vouhé PR, Trinquet F, Lecompte Y, Vernant F, Roux PM, Touati G, et al. Aortic coarctation with hypoplastic arch: results of extended end-to-end aortic arch anastomosis. J Thorac Cardiovasc Surg. 1988;96:557-63.

17. Jahangiri M, Shinebourne EA, Zurakowski D, Rigby ML, Redington AN, Lincoln C. Subclavian flap aotoplasty: does the arch look after itself? J Thorac Cardiovasc Surg. 2000;120:224-9.

18. Siewers RD, Ettedaui J, Tallman T, del Nido PJ. Coarctation and hypoplasia of the aortic arch: will the arch grow? Ann Thorac Surg. 1991;52:608-13.

19. Weber HS, Cryan SE, Gzeszczak M, Myers J, Gleason MM, Baylen BG. Discrepancies in aortic arch growth explain aortic arch gradients during exercise. J Am Coll Cardiol. 1993;21:1002-7. 